Available online on 15.3.2017 at http://ujpr.org
Universal Journal of Pharmaceutical Research
An International Peer Reviewed Journal
Open access to Pharmaceutical research

\title{
FABRICATION AND CHARACTERIZATION OF EZETIMIBE SOLID DISPERSION FOR SOLUBILITY ENHANCEMENT Usman Mohammed Jajere ${ }^{1}$, , Achadu $\mathrm{AE}^{2}$ (D) \\ ${ }^{l}$ Department of Pharmacognosy and Drug development, Ahmadu Bello University zaria, Nigeria. ${ }^{2}$ Faculty of Natural Science, Kogi State University, Anyigba, Kogi State, Nigeria.
}

\section{ABSTRACT}

Objective: The objective of the present study was to formulate solid dispersions (SD) of Ezetimibe to improve the solubility and dissolution rate to facilitate faster onset of action. Ezetimibe is poorly water soluble BCS class II drug and used as a hypolipidemic agent. It has poor bioavailability (35-65\%) due to its low dissolution profile in gastro intestinal tract.

Methods: In the present study, eight solid dispersion formulations of Ezetimibe with polymers PEG-4000 and PEG-6000 were prepared by solvent evaporation and fusion methods. Solid dispersion formulations were characterized by content uniformity, flow properties and in vitro dissolution studies.

Results: The solubility of Ezetimibe powder in distilled water at $37 \pm 0.5^{\circ} \mathrm{C}$ was $2.37 \pm 0.14 \mu \mathrm{g} / \mathrm{ml}$, whereas solubility of the solid dispersion formulations was in the range of 322.43-37.48 $\mu \mathrm{g} / \mathrm{ml}$. Percent yield of eight solid dispersion formulations of Ezetimibe lies in range of 98.20 to $99.42 \% \mathrm{w} / \mathrm{w}$.

Conclusion: Present study concluded that the Ezetimibe solid dispersion formulations are a suitable approach to improve the solubility and dissolution rate of ezetimibe than pure form of drug.

Keywords: Ezetimibe, PEG-4000, PEG-6000, solid dispersion.

Article Info: Received 2 January 2017; Revised 12 February; Accepted 7 March, Available online 15 March 2017

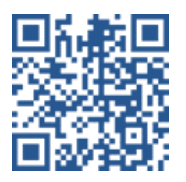
Cite this article-

Jajere UM, Achadu AE. Fabrication and characterization of ezetimibe solid dispersion for solubility enhancement. Universal Journal of Pharmaceutical Research 2017; 2(1): 11-14.

DOI: http://doi.org/10.22270/ujpr.v2i1.R3

Address for Correspondence:

Usman Mohammed Jajere, Department of Pharmacognosy and Drug development, Ahmadu Bello University zaria, Nigeria; Email: ujajere076@gmail.com

\section{INTRODUCTION}

Solubility is an important aspect for oral dosage forms, to deliver required drug concentration in systemic circulation to produce desired pharmacological response ${ }^{1}$. On an average more than $90 \%$ of available drugs have poor solubility, poor permeability, or both ${ }^{1}$. For this reason there is always a need to use high doses of poor soluble drugs to achieve minimum effective concentration of drug in systemic circulation ${ }^{2}$. There are so many approaches to enhance the solubility of such poorly water-soluble drugs like particle-size reduction, salt formation, solubilization, and complexation with $\beta$ cyclodextrins. All these methods suffer from one or the other drawbacks ${ }^{3}$. Among various approaches, the solid-dispersion technique is the most successful in improving the dissolution and bioavailability of poorly soluble, active pharmaceutical ingredients because it is simple, economical and advantageous ${ }^{4}$. A solid dispersion can be defined as "dispersion of one or more active ingredients in an inert carrier matrix in solid-state". Solid dispersion refers to a group of solid products consisting of at least two different components, generally a hydrophilic matrix and a hydrophobic drug ${ }^{5}$. The drug can be dispersed molecularly, in amorphous particles (clusters) or in crystalline particles by various methods. It enhances solubility by reducing particle aggregation, eliminating crystalanity, increasing wettability, dispersabilty and altering the surface properties of drug particles $^{6}$. When solid-dispersion is exposed to aqueous media the carrier dissolves and drug releases as fine colloidal particles, the resulting enhanced surface area produces higher dissolution rate and bioavailability of poorly water soluble drugs $^{7}$. Ezetimibe is a BCS class II drug. Ezetimibe is poorly water soluble drug and act as a hypolipidemic agent ${ }^{8}$. Ezetimibe decreases plasma cholesterol levels by inhibiting the cholesterol absorption in the intestine. It has $35-65 \%$ of bioavailability due to its low dissolution profile in gastro intestinal tract ${ }^{9}$. Ezetimibe binds to a carrier of cholesterol absorption, the Niemann Pick C1Like 1 (NPC1L1) protein on the gastrointestinal tract epithelial cells and in hepatocytes thus decreasing the LDL in the body and prevent various life threatening 
diseases. In the present investigation an attempt has been made to increase the dissolution profile of Ezetimibe by solid dispersion ${ }^{10}$. The aim of the present study was to prepare solid dispersions in order to achieve increased dissolution rates. Therefore, in the present study, solid dispersions of Ezetimibe were prepared by solvent evaporation technique and fusion method. Acetone was selected as a solvent as drug has highest solubility in this solvent. Acetone is categorized under class II solvents, less toxic than other chlorinated solvents can be easily evaporated and recovered because of its low boiling point.

\section{MATERIALS AND METHODS}

Ezetimibe was gift sample from Afrab-chem ltd, Nigeria. PEG 4000 and PEG 6000 were obtained from Dana Drugs ltd, Lagos, Nigeria and all other reagents used were of analytical grade.

\section{Preparation of solid dispersions}

\section{Solvent Evaporation method}

Required amount of Ezetimibe was dissolved in $10 \mathrm{ml}$ of acetone. Accurately weighed carriers PEG 4000, PEG 6000 corresponding to different drug: carrier ratio by weight was dispersed in drug solution. The solvent was allowed to evaporate on water bath under occasional stirring at temperature of $40-42^{\circ} \mathrm{C}$ in a protected environmental condition containing an exhaust system. The dried mass was pulverized and was passed through a mesh sieve of number of 100 . The powder was subsequently dried at $40^{\circ} \mathrm{C}$ for 3 hours in a tray drier ${ }^{11}$.

\section{Fusion method}

In fusion method the binary solid dispersions were made using PEG-4000, PEG-6000 as carriers with varying drug: carrier ratios by the fusion method. Solid dispersion of Ezetimibe and carriers were obtained by melting carrier in a porcelain dish at 80 $85^{\circ} \mathrm{C}$ and to this Ezetimibe added with thorough mixing for 1-2 minutes followed by quick cooling. The dried mass was then crushed and passes through sieve no.40 to get uniform sized particles ${ }^{11}$.

\section{Solubility studies}

The solubility studies of different Ezetimibe and solid dispersion formulations of Ezetimibe were conducted in distilled water and phosphate buffer of 1.2, 6.8 and $7.4 \mathrm{pH}$. An excess amount of Ezetimibe solid dispersion was weighed and transferred into conical flasks which contain $10 \mathrm{ml}$ of media. The content in conical flask were sonicated for $2 \mathrm{hrs}$ at room temperature, there after the samples were placed on a shaker, agitated at room temperature for $48 \mathrm{hrs}$. After it, the suspensions were filtered through a Whatman filter paper. The filtrate was suitably diluted and analyzed spectrophotometrically at a wavelength of $232 \mathrm{~nm}$ using a double beam UV-Visible spectrophotometer ${ }^{0}$.

\section{Characterization of formulations}

Percent yield

Percent yield was determined by following formula

$$
\text { Yield }=\frac{\mathrm{a}}{\mathrm{b}+\mathrm{c}} \mathrm{X} 100
$$

where, $\mathrm{a}$ is the weight of solid dispersion sifted through a 60 number mesh sieve, b is the weight of Ezetimibe taken for solid dispersion preparation, and $\mathrm{c}$ is the weight of polymer taken for solid dispersion preparation $^{14}$.

\section{Angle of Repose}

The angle of repose has been used to characterize the flow properties of solids. It is a characteristic related to inter particulate friction or resistance to movement between particles ${ }^{14}$. This is the maximum angle possible between surface of pile of powder or granules and angle of repose is determined by following formula:

$$
\tan \theta=\frac{\mathrm{h}}{\mathrm{r}}
$$

Where,

$\theta=$ angle of repose, $h=$ height of the cone, $r=$ radius of the cone base

\section{Bulk density}

It is the ratio of total mass of powder to the bulk volume of powder. It was measured by pouring the weighed powder into a measuring cylinder and the volume was noted ${ }^{\mathbf{1 5}}$. It is expressed in $\mathrm{gm} / \mathrm{ml}$ and is given by

$$
\text { Bulk density }=\frac{\text { Mass of powder }}{\text { Bulk volume of powder }}
$$

\section{Tapped density}

Tapped density was determined by using graduated cylinder. An accurately weighed sample was carefully added to the graduated cylinder with the aid of funnel. The initial volume was noted and the sample was tapped on a horizontal base. Tapping was continued until no further reduction in sample volume was observed $^{16}$.

$$
\text { Tapped density }=\frac{\text { Mass of powder }}{\text { Tapped volume of powder }}
$$

\section{Carr's Index}

It indicates the ease with which a material can be induced to flow and powder compressibility ${ }^{0}$. It is expressed in percentage and is given by

$$
\text { Carr, s Index }=\frac{\text { Tapped density }- \text { Bulk density }}{\text { Tapped density }} \text { x100 }
$$

\section{Hausner's ratio}

Hausner ratio $(\mathrm{Hr})$ is an indirect index of ease of powder flow ${ }^{0}$. It is calculated by the following formula:

$$
\text { Hausner's ratio }=\frac{\text { Tapped density }}{\text { Bulk density }}
$$

\section{Drug content}

Solid dispersions (100 mg) were accurately weighed and dissolved separately in $100 \mathrm{ml}$ of $20 \% \mathrm{v} / \mathrm{v}$ acetic acid. The solution was suitably diluted and the absorbance was measured at $232 \mathrm{~nm}$. Drug content was calculated using the regression equation ${ }^{0}$.

\section{In vitro dissolution studies}

Ezetimibe a pure drug and solid dispersions were subjected to dissolution test using in-vitro dissolution rate apparatus-I of USP XXIV (Basket method). This test was performed using $1000 \mathrm{ml}$ of dissolution medium $(0.1 \mathrm{~N} \mathrm{HCL})$ at $37 \pm 2{ }^{0} \mathrm{C}$. Accurately weighed samples (plain drug and surface solid dispersions) of drug were filled in ' 00 ' size hard gelatin capsule by hand filling method and placed in basket of dissolution apparatus which was rotated at $50 \mathrm{rpm}$. A $5 \mathrm{ml}$ aliquot of dissolution medium was withdrawn and replaced with equal volume of fresh dissolution medium at 
appropriate time intervals and analyzed spectrophotometrically by measuring absorbance at $232 \mathrm{~nm}$.

\section{RESULTS AND DISCUSSION}

The equilibrium solubility data are presented in Table 2. The solubility of Ezetimibe powder in distilled water at $37 \pm 0.5^{\circ} \mathrm{C}$ was $2.37 \pm 0.14 \mu \mathrm{g} / \mathrm{ml}$, whereas solubility of the solid dispersion formulations was in the range of $322.43-37.48 \mu \mathrm{g} / \mathrm{ml}$. In other aqueous media i.e. in phosphate buffer of $\mathrm{pH} 1.2,6.8$ and 7.4 , there was increased solubility of solid dispersion formulations in comparison to pure drug. It was found that as the $\mathrm{pH}$ of the media increased, there was increase in solubility drug and solid dispersion formulations. These findings suggest that solid dispersions had much more enhanced equilibrium solubility as compared with pure drug powder and physical mixtures. Calculated percent yield of eight solid dispersion formulations of Ezetimibe lies in range of 98.20 to $99.42 \% \mathrm{w} / \mathrm{w}$.

Table 1: Composition of solid dispersion formulations of Ezetimibe.

\begin{tabular}{lllll}
\hline $\begin{array}{l}\text { Formulation } \\
\text { code }\end{array}$ & Carrier & $\begin{array}{l}\text { Drug: } \\
\text { Carrier }\end{array}$ & Method & Acetone \\
\hline SD1 & PEG 4000 & $1: 1$ & Fusion method & q.s. \\
SD2 & PEG 4000 & $1: 3$ & Fusion method & q.s. \\
SD3 & PEG 6000 & $1: 1$ & Fusion method & q.s. \\
SD4 & PEG 6000 & $1: 3$ & Fusion method & q.s. \\
SD5 & PEG 4000 & $1: 1$ & Solvent evaporation method & q.s. \\
SD6 & PEG 4000 & $1: 2$ & Solvent evaporation method & q.s. \\
SD7 & PEG 6000 & $1: 1$ & Solvent evaporation method & q.s. \\
SD8 & PEG 6000 & $1: 2$ & Solvent evaporation method & q.s. \\
\hline
\end{tabular}

Table 2: Solubility study of Ezetimibe and solid dispersion formulations of Ezetimibe.

\begin{tabular}{lllll}
\hline Sample & \multicolumn{4}{c}{ Solubility $(\boldsymbol{\mu g} / \mathbf{m l})$} \\
\cline { 2 - 5 } & $\begin{array}{l}\text { Distilled } \\
\text { Water }\end{array}$ & $\begin{array}{l}\mathbf{1 . 2} \mathbf{~ p H} \\
\text { buffer }\end{array}$ & $\begin{array}{l}\mathbf{6 . 8} \mathbf{~ p H} \\
\text { buffer }\end{array}$ & $\begin{array}{l}\mathbf{7 . 4} \mathbf{~ p H} \\
\text { buffer }\end{array}$ \\
\hline Pure drug & $2.37 \pm 0.14$ & $3.37 \pm 0.14$ & $4.42 \pm 0.09$ & $5.31 \pm 0.06$ \\
SD1 & $22.43 \pm 0.25$ & $23.48 \pm 0.13$ & $24.57 \pm 0.26$ & $25.95 \pm 0.14$ \\
SD2 & $24.59 \pm 0.09$ & $26.81 \pm 0.26$ & $29.44 \pm 0.07$ & $31.59 \pm 0.26$ \\
SD3 & $23.47 \pm 0.07$ & $26.64 \pm 0.07$ & $28.58 \pm 0.42$ & $29.74 \pm 0.25$ \\
SD4 & $33.56 \pm 0.11$ & $37.83 \pm 0.04$ & $36.46 \pm 0.18$ & $39.85 \pm 0.16$ \\
SD5 & $26.87 \pm 0.26$ & $28.55 \pm 0.08$ & $32.74 \pm 0.33$ & $29.73 \pm 0.09$ \\
SD6 & $37.48 \pm 0.31$ & $39.51 \pm 0.15$ & $40.57 \pm 0.41$ & $41.66 \pm 0.07$ \\
SD7 & $29.41 \pm 0.16$ & $33.74 \pm 0.32$ & $35.83 \pm 0.09$ & $36.85 \pm 0.14$ \\
SD8 & $30.46 \pm 0.08$ & $36.78 \pm 0.42$ & $37.58 \pm 0.25$ & $38.72 \pm 0.25$ \\
\hline
\end{tabular}

Out of all the formulation of batch SD6 have shown highest yield $(99.42 \%)$ whereas formulation of batch SD2 have shown minimum yield $98.20 \%$. Solid dispersion formulations of Ezetimibe were characterized with respect to angle of repose, bulk density, tapped density, Carr's index, and Hausner's ratio (Table 3). Angle of repose was less than $35^{\circ}$ and Carr's index values were less than 21 and Hausner's ratio was less than 1.25 for all the batches indicating good flow properties. The drug content in all Ezetimibe solid dispersion formulations containing PEG 4000 as well as PEG 6000 is above than $98.15 \%$ as shown in Table 3. The drug content was found to be minimum (98.15\%) for SD7 whereas SD6 have shown maximum $(99.66 \%)$ drug content. PEG 6000 containing formulations showed better results than PEG 4000 formulations because of its high molecular weight which are responsible for the formation of fine microcrystal and absence of drug clusters. Dissolution data of Ezetimibe solid dispersion formulations are reported in Figure 1 and Figure 2. From the result, it can be seen that all the prepared solid dispersion showed an enhancement in the dissolution rate of the drug compared to plain drug. Solid dispersions prepared by using PEG 4000 showed enhanced dissolution when compared to other PEG 6000. The rank order of dissolution rate improvement for various carriers are; PEGS 4000>PEG 6000.

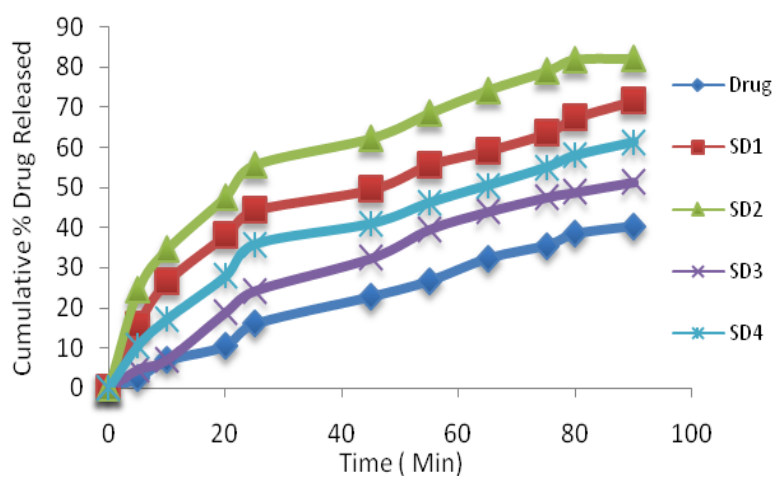

Figure 1: Dissolution profile of Ezetimibe solid dispersion formulations of batch SD1-SD4.

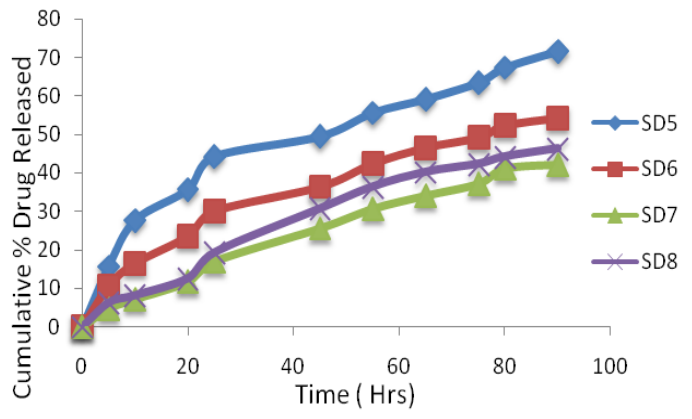

Figure 2: Dissolution profile of Ezetimibe solid dispersion formulations of batch SD5-SD8. 


\section{CONCLUSION}

Eight formulations were prepared by the solvent evaporation method and fusion method. All prepared solid dispersion formulations showed significantly higher drug dissolution in comparison with pure drug. In the solid dispersion there are many mechanism are responsible for exhibiting faster release like the decrease in particle size, partly to the wettability and to some extent to increase in the solubility of the drug due to the solubilising effect of carrier used or to the increase in surface area of the drug in the product. From the obtained results it can be concluded that solid dispersions improved the dissolution rate of poorly soluble drug Ezetimibe. The results of the Ezetimibe solid dispersion was indeed promising although more evaluation is needed before it can be finally recommended for capsule or tablet dosage form of Ezetimibe.

\section{AUTHOR'S CONTRIBUTION}

The manuscript was carried out, written, and approved in collaboration with all authors.

\section{ACKNOWLEDGEMENTS}

The authors extend their thanks and appreciation to the Ahmadu Bello University zaria, Nigeria to provide necessary facilities for this work.

\section{CONFLICT OF INTERESTS}

Authors report no conflict of interests regarding the publication of this paper.

\section{REFERENCES}

1.Otsuka M, Onoe M, Matsuda Y. Hygroscopic stability and dissolution properties of spray-dried solid dispersions of furosemide with eudragit. J Pharm Sci 2006; 82(1): 32-38. https://doi.org/10.1002/jps.2600820108

2. Martinez-Oharriz MC, Rodrig-Espinosa C, Martin C, Goni MM, Trosllarduya MC, Sanchez, M. Solid dispersions of diflunisal-PVP: Polymorphic and amorphous states of the drug. Drug. Dev. Ind Pharm 2002; 28(6): 717-725. https://doi.org/10.1081/ddc-120003864

3. Serajuddin, A. Solid dispersion of poorly water-soluble drugs: early promises, subsequent problems, and recent breakthroughs. J Pharm Sci 1999; 88(10):1058-1066. https://doi.org/10.1021/js980403l

4.Cassidy OE, Rouchotas C. Comparison of surface modification and solid dispersion techniques for drug dissolution. Int J Pharm 2000; 195(2):1-6. https://doi.org/10.1016/S0378-5173(99)00350-6

5. Sekiguchi K, Obi N. Studies on absorption of eutectic mixture absorption of fused conglomerates of chloramphenicol and urea in rabbits. Chem Pharm Bull (Tokyo) 1964; 12: 134-144. https://doi.org/10.1248/cpb.12.134

6. Barakat NS, Elanazi FK, Almurshedi AS. The influence of various amphiphilic excipients on the physicochemical properties of carbamazepine-loaded microparticles. J Microencapsulation 2009; 26(3): 251-262.

https://doi.org/10.1080/02652040802305113
7. Papageorgiou GZ, Bikiaris D, Karavas E, Politis S, Docoslis A, Park Y, Stergiou A, Georgarakis E. Effect of physical state and particle size distribution on dissolution enhancement of nimodipine/ PEG solid dispersions prepared by melt mixing and solvent evaporation. AAPS J 2006; 8(4): E623-E631. https://doi.org/10.1208/aapsj080471

8. Patel RP, Patel MM. Physiochemical characterization and dissolution study of solid dispersion of lovastatin with polyethylene glycol 4000 and polyvinylpyrrolidone K30. Pharm Dev Technol 2007; 12(1):21-33. https://doi.org/10.1080/10837450601166510

9. Kosoglou T, Statkevich P, Johnson-Levonas AO, Paolini JF, Bergman AJ, Alton KB. Ezetimibe: a review of its metabolism, Pharmacokinetics and drug interactions. Clin. Pharmacokinet 2005; 44 (5): 467-494.

https://doi.org/10.2165/00003088-200544050-00002

10. Martindale. The complete drug reference, $32^{\text {nd }}$ ed., London: the pharmaceutical press $1999 ; 1473$ https://doi.org/10.3163/1536-5050.100.1.018

11. Garcia Calvo M, Lisnock J, Bull HG, Hawes BE, Burnett DA, Braun MP, The target of ezetimibe is niemann-pick c1like 1 (npc111). Proc Natl Acad Sci USA 2005; 102: 8132. https://doi.org/10.1073/pnas.0500269102

12. Huang J, Wigent RJ, Schwartz JB. Nifedipine molecular dispersion in microparticles of ammonio methacrylate copolymer and ethylcellulose binary blends for controlled drug delivery: Effect of matrix composition. Drug Dev Ind pharm 2006; 32, 1185-1197. https://doi.org/10.1080/03639040600832827

13. Azarmi S, Roa W, Lobenberg R. Current perspectives in dissolution testing of conventional and novel dosage forms. Int J Pharmaceutics 2007; 328(1): 12-21. https://doi.org/10.1016/j.ijpharm.2006.10.001

14. Costa P, Sousa Lobo JM. Modeling and comparison of dissolution profiles. Eur J Pharm Sci 2001;13:123133.https://doi.org/10.1016/S0928-0987(01)00095-1

15. Balasubramaniam J, Rajesh Y, Bindu K, Hemalatha T, Swetha M, Vinay UR. Enhanced dissolution and bioavailability of raloxifene hydrochloride by co-grinding with different superdisintegrants. Chem Pharm Bull 2010; 58: 293-300. https://doi.org/10.1248/cpb.58.293

16. Chaulang G, Patel P, Hardikar S, Kelkar M, Bhosale A, Bhise B: Formulation and evaluation of solid dispersions of furosemide in sodium starch glycolate. Trop J Pharm Res 2009; 8(1): 43-51

17. Tran TD, Tran PHL, Choi HG, Han HK, Lee BJ. The roles of acidifiers in solid dispersion and physical mixtures. Int $\mathbf{J}$ Pharm 2010; 384(1): 60-66. https://doi.org/10.1016/j.ijpharm.2009.09.039

18. El-Maradny HA, Mortada SA, Kamel OA, Hikal AH. Characterisation of ternary complexes of meloxicam-HP $\beta C D$ and PVP or L-arginine prepared by the spray drying technique. Acta Pharm 2008; 58: 455-466. https://doi.org/10.2478/v10007-008-0029-9

19. Ritger PL, Peppas NA. A Newa M, Bhandari KH, Kim JO. Enhancement of solubility, dissolution and bioavailability of ibuprofen in solid dispersion systems. Chem Pharm Bull 2008; 56(4):569-74.https://doi.org/10.1248/cpb.56.569

20. Mehta S, Joseph NM, Fitsum FS, 1, Palani S, Improving solubility of bcs class ii drugs using solid dispersion: a review. J Drug Deliv Therap 2014; 4(3), 713.https://doi.org/10.22270/jddt.v4i3.844

21. Chun-Woong P. Preparation and in vivo evaluation of immediate-release pellet containing celecoxib solid dispersion. J Pharm Invest 2012; 42; 121-126. https://doi.org/10.1007/s40005-012-0021-8 